\title{
O uso de agrotóxicos pelos agricultores da comunidade Baixa do Juá, Santana de Mangueira - PB
}

\section{The uses off pesticides by community farmers Baixa do Juá, Santana de Mangueira - $\boldsymbol{P B}$}

\author{
Jocimario A. Pereira ${ }^{1}$, Joelma F. V. de Jesus ${ }^{2}$, Natanaelma C. da Silva ${ }^{3}$
}

\begin{abstract}
Resumo: Os agrotóxicos foram introduzidos no Brasil na década de 60, na época o governo criou um plano nacional de defensivos agrícolas, baseado e argumentado pela "Revolução Verde", onde as práticas modernas se expandem, uso de máquinas, sementes geneticamente modificadas aparecem e o uso de defensivos químicos (agrotóxicos) se populariza. Com políticas publicas favoráveis a esse setor, hoje o país passou a ser apontado em varias pesquisas como maior consumidor de insumos químicos. Desta forma interiorizando no Brasil novas tecnologias de manejo e práticas agrícolas como uso de agrotóxicos. Este trabalho objetiva investigar o uso de defensivos químicos na produção agrícola da comunidade Baixa do Juá município de Santana de Mangueira - PB, avaliando as possíveis consequências dessa prática no âmbito pessoal e profissional. O trabalho constou de pesquisa quantitativa e qualitativa, com pesquisa documental, pesquisa de campo, entrevistas e questionários, junto aos produtores associado à ASPROBAJA (Associação dos Produtores Rurais da comunidade Baixa do Juá) que residem no perímetro da comunidade. A conjectura do trabalho revela a situação de precariedade ao assistencialismo agrícola, em pequenas comunidades, abandonada pelo poder público, expondo a necessidade de um trabalho educativo e estruturante de dispositivos que possam fortalece o setor.
\end{abstract}

Palavras-chaves - Defensivos Químicos; Agricultura Familiar; Meio Ambiente; Associação.

\begin{abstract}
The pesticides were introduced in Brazil in the 60s, then the government created a national plan of pesticides based and argued by the "Green Revolution", where modern practices expand, use machines, genetically modified seeds appear and the use of agrochemicals (pesticides) becomes popular. With favorable public policies in this sector, today the country has to be pointed out in several surveys as largest consumer of chemical inputs. Thus in Brazil internalizing new management technologies and agricultural practices such as pesticide use. This study aims to investigate the use of chemical pesticides in the community of agricultural production Baixa do Juá city of Santana de Mangueira - PB, evaluating the possible consequences of this practice on personal and professional level. The work consisted of quantitative and qualitative research , with desk research, field research, interviews and questionnaires, with producers associated with ASPROB AJA (Association of Rural Producers of Baixa do Juá community) residing in the community perimeter. The conjecture of work reveals the precarious situation in the agricultural welfare, in small communities, abandoned by the government, exposing the need for an educational and structural work of devices that can strengthen the sector.
\end{abstract}

Keywords - Chemical pesticides; Family Agriculture; Environment; Association.

\footnotetext{
*Autor para correspondência

Recebido para publicação em 22/01/2015; aprovado em 22/05/2015

${ }^{1}$ Licenciado em Ciências Agrarias, UFPB, Bananeiras; 83 9655-1591, mario.alves_@ hotmail.com

${ }^{2}$ Licenciada em Ciências Agrarias, Mestre em Agroecologia, UFPB, joelmaufpb@ gmail.com

${ }^{3}$ Licenciada em Ciências Agrarias, Mestre em Agroecologia, UFPB, ampnatanaelma2@yahoo.com.br
} 


\section{INTRODUÇÃO}

A agricultura é a base da sociedade, devido o fornecimento de alimento para toda humanidade há mais de dez mil anos. No decorrer desses anos o seu desenvolvimento foi sendo desencadeado na mais variadas escalas e metodologias, se modernizando e se mecanizando, substituindo, em muitos casos, o trabalho braçal. Porém, alguns setores e ações ainda mantém certo paralelo com atividades milenares, onde podemos citar o uso de força animal no preparo do solo e o cultivo manual de determinadas culturas.

Desta forma formando dois eixos, agricultura tradicional e agricultura moderna. Onde a agricultura tradicional é depende-te das condições naturais e utiliza-se de técnicas ancestrais para a produção, enquanto a agricultura moderna é baseada no número maior de produção, alavancada pela Revolução Industrial, conforme Dias (2009).

Sendo a produção alimentar advinda da agricultura, e a população mundial crescendo de forma avassaladora, a preocupação de sua modernização e aumento de produção foi/são visíveis, para tal, muitas políticas em prol dessas atividades foram colocadas em práticas, como modificação de sementes, uso de insumos químicos e abertura de crédito para tais ferramentas. Essas ações acarretaram na chamada "Revolução Verde" ideologicamente trazendo a modernização da agricultura e assim aumentando a produção, o que poderia acabar com a fome no mundo. Segundo Andrades e Ganimi (2007) esse discurso foi orquestrado por grupos privados financiadores do projeto, e levou esses mesmo grupos a expandir mercado consumidor, com vendas de insumos agrícolas.

Londres (2011) afirma que com "Revolução Verde" as práticas modernas se expandem, uso de máquinas, sementes geneticamente modificadas aparecem e o uso de defensivos químicos (agrotóxicos) se populariza, sendo que as implantações dos agrotóxicos surgiram de forma impulsionada pelo fim das grandes guerras quando a indústria que fabricava veneno para armas químicas sentiram na agricultura um novo mercado.

No Brasil, as politicas públicas de vários governos demostram essa tendência. Assim, o país passou a ser apontado em várias pesquisas, como um dos principais consumidores de agrotóxicos do mundo, podendo citar a pesquisa intitulada "Regulation off Pesticides: A Comparative Analysis" divulgado em 2013, nos EUA. Da mesma forma como a Agência Nacional de Vigilância Sanitária (ANVISA) que revela preocupação não apenas com a quantidade, mas com a forma que esses produtos estão sendo utilizados em nosso país. Segundo a Agência, em relatório de 2013 esses "dados são preocupantes necessitando de maior formação por parte dos agricultores".

Diante das políticas públicas para uma "agricultura moderna", chegam aos pequenos agricultores do interior do Brasil novas tecnologias de manejo e práticas agrícolas. A partir dessa percepção, é necessário à investigação e análise de como está sendo o uso de defensivos químicos nas lavouras da agricultura familiar.

A definição literária para defensivos químicos são muitos: agrotóxico, praguicidas, pesticidas, produtos fitossanitários, ou seja, uma vasta nomenclatura para diversos produtos da mesma ordem. No nosso país, é definido pela Lei 7.802, de 11 de julho de 1989 como agrotóxicos:

Os produtos e os agentes de processos físicos, químicos ou biológicos, destinados ao uso nos setores de produção, no armazenamento e beneficiamento de produtos agrícolas, nas pastagens, na proteção de florestas, nativas ou implantadas, e de outros ecossistemas e também de ambientes urbanos, hídricos e industriais, cuja finalidade seja alterar a composição da flora ou da fauna, a fim de preservá-las da ação danosa de seres vivos considerados nocivos; substâncias e produtos, empregados como desfolhantes, dessecantes, estimuladores e inibidores de crescimento (PRESIDÊNCIA DA REPÚBLICA, 1989).

Esses produtos foram introduzidos no Brasil na década de 60, na época o governo criou um plano nacional de defensivos agrícolas. Atendendo as politicas publicas da "Revolução Verde" dentro do pacote de modernização agrícola concedia credito rural ao uso de agrotóxico (Giraldo, 2014). As concessões fiscais a esses produtos, fez com que a indústria desse ramo, cresce e se perpetuasse no nosso país, conforme Londres (2011), dessa forma popularizando técnicas e praticas que se utiliza desses produtos.

Devido todo aparato de atratividade pelo governo e suas políticas, os agrotóxicos chegam à agricultura familiar brasileira. Sendo importante citar que dados do Ministério de Desenvolvimento Social e Combate a Fome (MDS) a agricultura familiar é responsável por $70 \%$ da produção de alimentos da mesa do brasileiro. De acordo com o Ministério da Saúde (MS) ocorreu 208,8 mil casos de intoxicação por agrotóxicos entre os anos de 1985 e de 2008. Conforme Peres e Moreira (2003) a contaminação atinge não apenas pessoas, mas o solo, a água e todo meio ambiente. O que fica evidente o impacto ambiental, social e econômico do uso desses produtos.

Os prejuízos vêm da vulnerabilidade e da socialização dos resultados negativos, a saúde humana está ligada a todos os fatores prejudicados, evidenciado por Carneiro (2007). E como decorrente de outros prejuízos as camadas de baixo poder aquisitivo sofre os maiores efeitos, como proposto por Porto (2007), e assim tendo uma sistematização onde todo país sai perdendo.

A Associação dos Produtores Rurais da Comunidade Baixa do Juá (ASPROBAJA) foi fundada em maio de 2001 com o desmembramento da comunidade Boa Vista. Sendo formada pelos produtores e residentes dos sítios: Baixa do Juá, Boa Vista II \& III, tendo como sede a pequena Escola Municipal Francisco Ramos de Moura localizada no sitio Boavista II município de Santana de Mangueira - PB.

A comunidade está situada á $19 \mathrm{~km}$ da sede do município, porém mantém maiores vínculos comerciais com a cidade de Conceição - PB que fica apenas $13 \mathrm{~km}$ e o acesso é mais seguro. Atualmente a associação conta com 48 membros sendo que cerca de $50 \%$ desses não se encontram no perímetro da comunidade, porém mantém vínculo fiscal e comercial com a mesma.

Composta por mais de 1.000 ha, sendo que em nenhuma das propriedades há registro de reserva legal, apesar de todos os proprietários preservarem certas localidades, principalmente por ficarem longe das sedes. Com o crescente do fenômeno êxodo rural e anos de prejuízos devido à seca, 
má gestão agrícola, falta de assistencialismo entre outros fatores, boa parte das terras ficam intactas (sem serem exploradas/cultivadas), outras partes são utilizadas apenas para retirada de madeira para manutenção da propriedade (construções, lenha, etc.) ou na época de inverno para soltar animais.

Na década de 80 os sítios que formam a ASPROBAJA foram grandes produtores de algodão arbóreo, porém com a chegada do bicudo (Anthonomus grandis) por volta de 1990, devastou todas as plantações e o que levou a comunidade a um colapso econômico. Com o fim das plantações de algodão os produtores apenas exercia agricultura de subsistência, com a criação de animais (bovinos, ovinos, caprinos, aves, etc.) e plantações de milho e feijão, como constatado por Diniz (2014).

Nesse período do fim do "ouro branco" do sertão, os produtores da localidade, foram seduzidos pelos financiamentos agrícolas concedidos pelo Banco do Nordeste do Brasil (BNB), os financiamentos tinham como principais finalidades, construção de cerca, pequenos açudes, construção de espaço para guardar silagem (silos), aquisição de bovinos e construção de pastagem, Diniz (2014).

Foi nesse momento que a comunidade entrou em contato com os produtos químicos para auxiliar em lavouras, a recomendação do BNB era que fossem derrubadas e queimadas as vegetações nativas e introduzidas gramíneas e leguminosas exóticas, essa prática citada por um resumo doutrinário elaborado pela Agroceres e publicado pelo BNB e o Departamento Nacional de Obras Contra a Seca (DNOCS). Com a introdução de plantas exóticas, o trato cultural se torna comum uso de agrotóxicos para controle de pragas e doenças das pastagens, porém nenhum informativo ou treinamento foi repassado para os produtores, nem pela EMATER (Empresa de Assistência Técnica e Extensão Rural), ou qualquer outro empresa ou pessoa física ligada à extensão rural.

Esse trabalho objetiva investigar o uso de defensivos químicos na produção agrícola da comunidade Baixa do Juá município de Santana de Mangueira - PB, avaliando as possíveis consequências dessa prática no âmbito pessoal e profissional.

\section{MATERIAL E MÉTODOS}

$\mathrm{O}$ trabalho foi realizado com os produtores associados à ASPROBAJA que residem no perímetro da comunidade, que é formada por três sítios: Baixa do Juá, Boa Vista II e III, todo município de Santana de Mangueira, cidade situada na micro região de Itaporanga, sertão da Paraíba. A cidade tem população estimada em 5.257 habitantes com uma área de 402, $152 \mathrm{Km}^{2}$ (IBGE, 2014).

Realizou-se pesquisa quantitativa e qualitativa, com pesquisa documental, pesquisa de campo, entrevistas e questionários. De acordo com Moreira (2009), a junção da abordagem quantitativa e qualitativa fornece o embasamento para o estudo, qualificado e justificando os resultados, formando assim uma articulação entre os métodos.

$\mathrm{Na}$ pesquisa documental da associação, procurou-se entender sua formação, história e situação. Essa parte da atividade foi integrada juntamente com entrevistas a cinco agricultores que fazem parte do conselho da associação, entrevista coordenada por cinco tópicos (perguntas) subjetivos, para descrever uma cronologia, sócio histórica de fatos importantes da comunidade e seus moradores, valendo salientar que "a análise documental busca identificar informações factuais nos documentos a partir de questões e hipóteses de interesse" (CAULLEY, 1981), já entrevista procura obter algumas informações, através dá padronização de perguntas, com assunto pré-definidos, porém mantendo um tom de conversa informal, tendo à intenção de manter o entrevistado a vontade, mas sem sair do tema, como Boni e Quaresma (2005) orientar.

A pesquisa de campo foi realizada com observação de procedimentos cotidianos dos agricultores e aplicação de questionário com 10 "chefes" de família associados que residem no perímetro da comunidade, os questionários formados por 16 perguntas, sendo 15 objetivas e uma subjetiva. Dessa forma o trabalho é voltado para uma descrição dos fatos e à situação da agricultura familiar dessa região, demostrando suas características de forma transparente, imparcial e com intuito científico.

Nessa prática aplicando um olhar social sobre a pesquisa, tratando a realidade humana na participação e ação dos objetos. Oportunizando o pesquisador fazer parte do estudo se inserindo no espaço analisado, com imparcialidade, porém permitindo maior aprofundamento dos resultados. E dessa forma assimilando o passo-a-passo dos resultados obtidos, com responsabilidade política e social da ideologia da comunidade através de todo processo construtivo de diálogo não doutrinário, sendo de parte a parte dinâmico modificável e construtivo, como retificam Brandão e Borges (2007).

\section{RESULTADOS E DISCUSSÃO}

A comunidade é formada por 48 associados, porém apenas 25 residem em um dos três sítios que fazem parte da ASPROBAJA, esses 25 associados fazem parte da composição de 10 famílias locais, os demais 23 associados praticaram êxodo rural, indo para as cidades circo vizinhas, ou grandes centros comercias como Petrolina - PE, porém mantém vínculo fiscal com a associação.

Entre as famílias que residem no local $80 \%$ são patriarcas (chefiadas por homens) e 20\% matriarcas (chefiadas por mulheres), o termo chefiadas se caracteriza na pesquisa como pessoa responsável pela administração da casa e da propriedade. As características administrativas das propriedades são bem semelhantes apesar da diferença de faixa etária dos seus proprietários e administradores (Figura 1), o que garante uma afinidade cultural entre as famílias distintas.

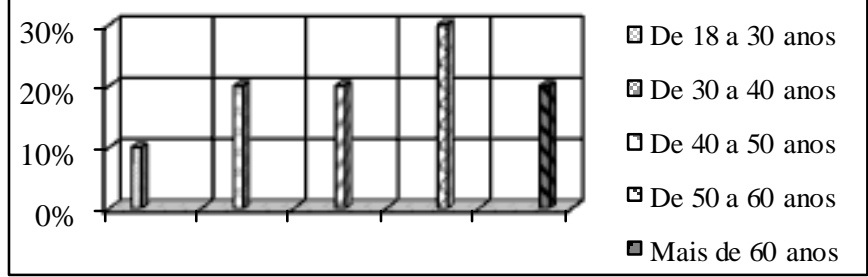

Figura 1. Faixa Etária dos "chefes" de família da SPROBAJA

Essa afinidade advém da conivência entre os moradores e as tradições locais, onde $10 \%$ dos entrevistados se 
encontram lá desde o nascimento, $20 \%$ estão lá de cinco a 15 anos, $40 \%$ de 15 a 25 anos e $30 \%$ a mais de 25 anos. Com esse tempo que reside na comunidade vale ressalta que $70 \%$ são proprietários de suas terras, os outros $30 \%$ são rendeiros (Pessoa que possui terras em arrendamento, caseiro, quem desfruta de uma propriedade pagando o preço do arrendamento) como pode ser visto na Figura 2.

\section{SITUAÇÃO DE POSSE DA TERRA}

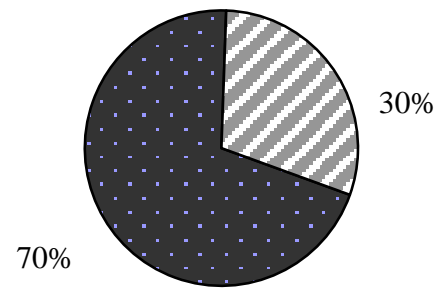

Dono da Terra

Figura 2. Situação de posse da terra

Essas propriedades possuem extensão variável onde $10 \%$ estão entre 20 e 50 ha, $30 \%$ de 50 a 100 ha e $40 \%$ mais de 100 ha, e apesar do tamanho das propriedades, apenas $40 \%$ tem a agricultura como renda principal, $60 \%$ tem como renda principal os benefícios públicos, como empregos na prefeitura, estado ou aposentadoria do INSS, esse dados da renda pode/devem está atrelado à área de exploração das terras, já que $30 \%$ exploram menos de um hectare, $10 \%$ de uma a cinco hectares, $10 \%$ de cinco a 10 ha, $40 \%$ de 10 a 20 ha e apenas $10 \%$ explora mais de 20 ha (Figura 3).

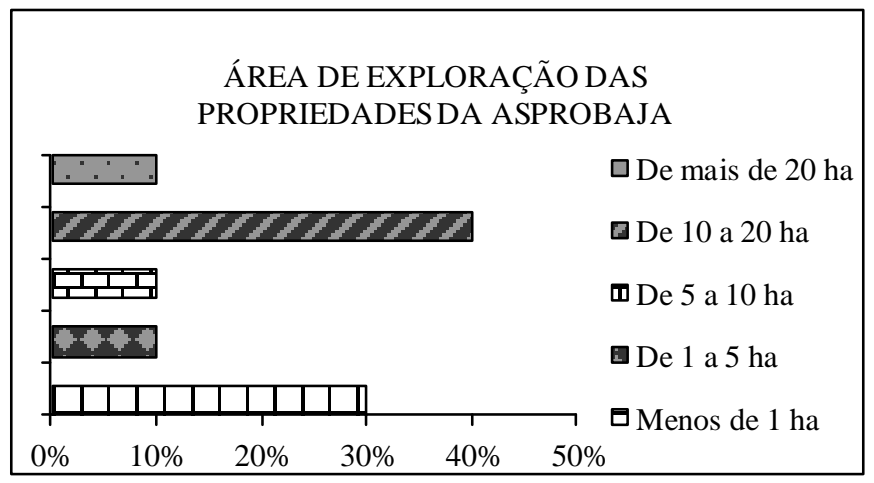

Figura 3. Área de exploração das propriedades da ASPROBAJA.

Nessa área explorada são efetuadas agricultura para o próprio consumo, onde $100 \%$ criam aves (galinha-caipira, pato, guiné), $70 \%$ criam bovinos, $60 \%$ suínos, $40 \%$ ovinos, $20 \%$ caprinos e $70 \%$ outros animais como equinos e muares, demostrando uma diversificação da pecuária na localidade, quanto a plantações $100 \%$ plantão feijão, milho e fazem pastagem, $40 \%$ plantam batata-doce e $60 \%$ plantam outras culturas, como hortaliças, plantas medicinais e frutas.

$\mathrm{Na}$ análise o que foi mais preocupante, é que $90 \%$ utilizam insumos químicos (agrotóxicos), como se pode ver a na Tabela 1. Valendo salientar que nessa lista constam produtos como Folidol que a venda e consumo são proibidos no Brasil, o que leva a grande preocupação, já que a recomendação é dada pela ANVISA. O Glifosato é outro que gera proporções de preocupação alarmante, que segundo
Aranda (2014) esse produto "aumenta a probabilidade de contrair câncer, sofrer abortos espontâneos e nascimentos com má formação".

Tabela 1. Lista de agrotóxicos, utilizados pelos associados da ASPROBAJA

\begin{tabular}{ccc}
\hline Defensivos químicos & $\begin{array}{c}\text { Classe toxicológica } \\
- \text { Periculosidade } \\
\text { ambiental }\end{array}$ & Classificação \\
\hline Barrage & Azul - III & Inseticida \\
Touchdown & Vermelho - II & Herbicida \\
$\begin{array}{c}\text { Glifosato } 480 \\
\text { agripec } \\
\text { Folidol }\end{array}$ & Vermelho - III & Herbicida \\
Roundup & Vermelho - I & Inseticida \\
& Verde - IV & Herbicida \\
& Vermelho - I & Inseticida
\end{tabular}

Decis 25 ec

O que pode ser observado, além do uso de produtos de alto risco e outros proibidos, não ocorre uso de EPI's, não há descarte correto das embalagens, nem mesmo leitura das orientações (bula dos produtos), ocorrendo uso demasiado, muitas vezes com aplicações bem acima do recomendado pelos fabricantes. Isso refle na concepção dos produtores, nos quais $100 \%$ acredita que uso de agrotóxicos faça mal a saúde, essa definição ocorre devido $40 \%$ dos entrevistados já terem se intoxicado em quanto trabalhava com aplicação dos agrotóxicos nas lavouras. No entanto com relação ao meioambiente $20 \%$ acreditam não trazer prejuízo, mas a maioria $80 \%$ (Figura 4), afirmam observa queda na produção aumento de pragas e deficiência dos solos e afirmam categoricamente que grande parte destes problemas vem do uso de agrotóxicos.

Mesmo com análise do entendimento dos agricultores com relação do uso de agrotóxico a saúde humana e meio ambiente, $70 \%$ dos agricultores entrevistados acreditam não ser possível produzir sem uso dos agrotóxicos e apenas $30 \%$ acreditam ser possível, relatam que a concorrência com produtos de outras regiões, é desleal e que mesmo com a produtividade baixa a melhor forma de produzir é utilizando de insumos químicos. Porém 90\% declaram que se conhecessem algum método eficiente de produção não utilizariam defensivos químicos, não usariam agrotóxicos em suas plantações e 10\% mesmo conhecendo esse tipo de método utilizariam os produtos químicos (Figura 5).

AGROTÓXICO PREJUDICA O MEIO AMBIENTE?

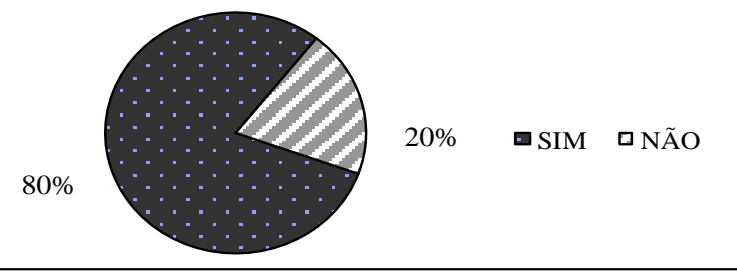

Figura 4. Porcentagem de agricultores que acreditam que o uso de agrotóxicos prejudica o meio ambiente 


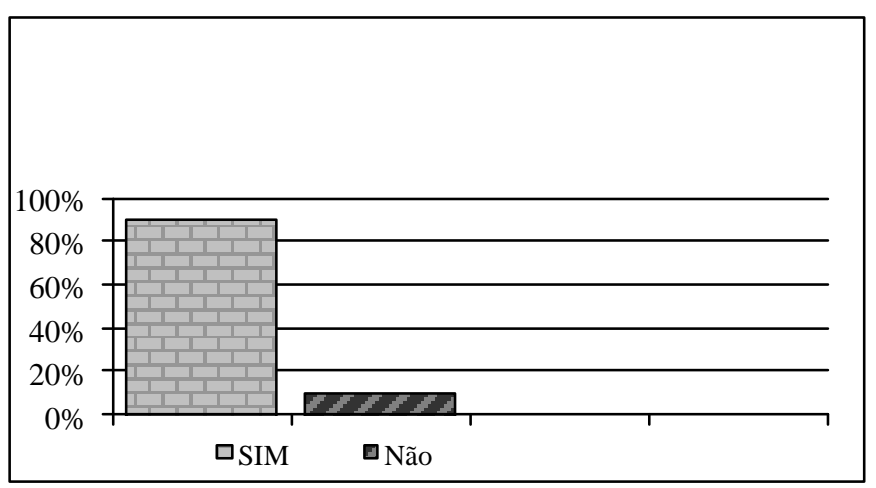

Figura 5. Agricultores que utilizariam outros produtos em substituição aos agrotóxicos (\%)

Em observação é eminente à falta de alternativas dos agricultores, que não dispõem de conhecimento e nem de assistência técnica, ao ponto de "esquecerem" suas culturas e práticas agrícolas, antes de infusão dos insumos químicos as suas ações. Podemos citar ainda anos de prejuízos, que veio desvalorizar certos métodos de trabalho.

Em entrevista aos membros do conselho foram relatados que não há grandes expectativas do futuro da comunidade, eles acreditam que com o passar do tempo todas as portas da comunidade fecharam, está percepção pode ser transcrita em um trecho da entrevista onde o Entrevistado A desabafa " $a$ nossa situação é desanimadora, não temos assistência, a seca castiga, não quero meu filho passando pelo que já passei, ele já estuda na rua e quero que vá mais longe ainda, quem sabe a capital, não quero que ela adoeça de novo com uso de veneno, e nem caleje a mão na enxada...”. Esse depoimento é marcante e atesta que o futuro dessa família na comunidade não é longo.

Em outra transcrição do Entrevistado B revela muita insatisfação com o poder publico "a comunidade é abandonada, não tem saúde, não há educação, segurança, ninguém nos enxerga há não ser no período eleitoral, eu bebo, como-o e vendo veneno, mas é pra sustentar a família não é por maldade... já senti o que os agrotóxicos pode fazer, porém não temos alternativa... esse é o mal de quem não estudou". Os agricultores se sentem acuados e sem muitas perspectivas de vida no campo, onde a realidade é essa mesma, ainda segundo os entrevistados só recebem visita de algum órgão ligado à agricultura (EMATER e Secretaria de Agricultura Municipal) na época do cadastramento do Seguro-safra, ou seja, anualmente.

A apreciação dos dados também revela o olhar dos moradores em relação à natureza, nos quais, já sente falta de enxames de abelhas, espécies vegetais como jitirana (Ipomoea sericophylla) que é importante planta na alimentação de animais na época de inverno, além da desertificação de áreas de roçado. Essa constatação é refletida na fala de todos os cinco entrevistados, no qual o Entrevistado C explana "não sei o que está acontecendo. Mas tem muita terra escravada (desertificada), antes não tinha isso... falta de chuva sei que não é, porque sempre choveu pouco, mas assisti na TV que agrotóxico causa isso... eu até tentei deixa de usar, mas quando a lagarta aparece ou passa veneno ou fica sem lavoura".

A perplexidade do Entrevistado C, é um reflexo contido em toda a comunidade que se sente abandonada, os resultados são claro, apesar de não haver análise de solo e dá água, há preocupação da comunidade com o uso de insumos químicos, entretanto não veem solução para este problema.

\section{CONCLUSÕES}

A conjectura do trabalho revela à situação de precariedade a assistência técnica agrícola, em pequenas comunidades, abandonada pelo poder público. A ASPROBAJA traz entranhada no seu contexto histórico, uma "metodologia revolucionária" que foi instruída por órgãos públicos (BNB e DONOCS), no início da década de 90, e que trazem com si até os dias atuais. O uso de insumos químicos (agrotóxicos) nas lavouras é corriqueiro, mesmo com problemas ocasionados aos moradores e sua propriedade, eles sentem-se obrigados ao uso desses produtos, já que não possuem alternativas visíveis, mas sabem que é um mal eminente à saúde e produtividade local.

As demonstrações dos elementos descritivos do trabalho apontam para um decrescimento e "infecção" da produção, proporcionado insatisfação do modo que trabalham. Este momento expõe a necessidade de um trabalho educativo e estruturante de dispositivos que possam fortalece as ações da localidade, para que esse cenário seja adernado e modificado. Com a revelação dessa situação, a construção de mais trabalhos seja possível, e assim proporcionar um presente e futuro próspero, aos moradores da ASPROBAJA.

\section{REFERÊNCIAS BIBLIOGRÁFICAS}

ADRIOLI, Antônio Inácio. O Roundup, o câncer e o crime do "colarinho verde". Disponível em: <http://www.espacoacademico.com.br/051/51 andrioli.htm >. Acesso em: 15 out. 2014.

ADAPAR. DECIS $25 \quad$ EC. Disponível em: <http://www.adapar.pr.gov.br/arquivos/File/defis/DFI/Bul as/Inseticidas/DECIS_25_EC.pdf $>$. Acesso em: 15 out. 2014.

ADAPAR. GLIFOSATO 480 AGRIPEC. Disponível em: $<$ http://www.adapar.pr.gov.br/arquivos/File/defis/DFI/Bul as/Herbicidas/GLIFOSATO_480_AGRIPEC.pdf>.

Acesso em: 10 out. 2014.

ADAPAR. TOUCHDOWN. Disponível em: <http://www.adapar.pr.gov.br/arquivos/File/defis/DFI/Bul as/Herbicidas/TOUCHDOWN.pdf>. Acesso em: 15 out. 2014.

ANDRADES, Thiago Oliveira de; GANIMI, Rosângela Nasser. REVOLUÇÃO VERDE E A APROPRIAÇÃO CAPITALISTA. Ces Revista, Juiz de Fora, v. 21, p.4356,2007

ANVISA. Relatório da ANVISA indica resíduo de agrotóxico acima do permitido. Disponível em: $<$ http://portal.anvisa.gov.br/wps/content/anvisa+portal/anv isa/sala+de+imprensa/menu+-

+noticias+anos/2013+noticias/relatorio+da+anvisa+indica + residuo+de+agrotoxico+acima+do+permitido>. Acesso em: 10 out. 2014. 
ARANDA, Darío. Após oito anos de pesquisas, relatório confirma vinculação glifosato/câncer. Disponível em: $<$ http://tudosobreplantas.wordpress.com/2014/10/09/aposoito-anos-de-pesquisas-relatorio-confirma-vinculacaoglifosatocancer/>. Acesso em: 03 nov. 2014.

ASCOM/MDS. Programa de Aquisição de Alimentos fortalece política de segurança alimentar. Disponível em:

<http://www.brasilsemmiseria.gov.br/noticias/ultimasnoticias/2014/marco/programa-de-aquisicao-de-alimentosfortalece-politica-de-seguranca-alimentar $>$. Acesso em: 11 mar. 14.

ASPROBAJA. Livro de Atas. Santana de Mangueira, 2001.

BONI, Valdete; QUARESMA, Silvia Jurema. Aprendendo entrevistar: Como fazer entrevistas em Ciências Sociais. In: Revista Eletrônica dos Pós-Graduandos em Sociologia Política da UFSC. Vol. $2 \mathrm{n}^{\circ} 1$, JaneiroJulho/2005, p.68-80.

BRANDÃO, Carlos Rodrigues; BORGES, Maristela Correa. A pesquisa participante: um momento da educação popular. Uberlândia: Popular, 2007.

CARNEIRO, F. et al. Dossiê da ABRASCO: Um alerta sobre os impactos dos agrotóxicos na saúde. Rio de Janeiro: ABRASCO, 30 abril de 2012.1'. Parte, 98p. CARSON, R. Primavera Silenciosa. São Paulo, Gaia Editora, 2010, 328p.

CASTRO, Maria Goretti Gurgel Mota de; FERREIRA, Aldo Pacheco; MATTOS, Inês Echenique. Uso de agrotóxicos em assentamentos de reforma agrária no Município de Russas (Ceará, Brasil): um estudo de caso. Disponível em:

<http://scielo.iec.pa.gov.br/pdf/ess/v20n2/v20n2a13.pdf>. Acesso em: 17 out. 2014

CAULLEY, DN. Document

Analysis in program

Evaluation (n. 60 na série paper andReport Series of the Research on Evaluation Program).Portland, Or.Northwest.Regional Educational laboratory, 1981.

DIAS, João. Agricultura Tradicional e Moderna. Disponível <http://joaoedias.blogspot.com.br/2009/05/agriculturatradicional-e-moderna.html>. Acesso em: 04 maio 2009.

DICIONARIO INFORMAL. Rendeiro. Disponível em: $<$ http://www.dicionarioinformal.com.br/rendeiro/>. Acesso em: 21 nov. 2014

DINIZ, Francisco Inácio. ENTREVISTA COM AGENTE RURAL, EXTENSIONISTA, ETC. Santana de Mangueira: UFPB - Estagio Supervisionado, 2014.

DINIZ, Francisco Inácio. Relatório de Estagio Supervisionado: Santana de Mangueira: UFPB, 2014.

DNOCS - Departamento Nacional de Obras de Combate a Seca. Melhores pastagens para o Nordeste. Agroceres, Fortaleza, 1979.
FAVERO, Silvio; SOUZA, Elizabeth Marmo de; MATIAS Rosemary. ECOTOXICIDADE DO PARATION METÍLICO E GLIFOSATO PARA Poecilia reticulata (PISCES: POECILIIDAE)

EM

LABORATÓRIO. Ensaios e Ciência: Ciências Biológicas, Agrárias e da Saúde, Anhaguera, v. 9, n. 2, p.315-324, ago. 2005.

GIRALDO, Lia. Há muitas evidências de danos dos agrotóxicos à saúde. Entrevista concedida a fundação Oswaldo Cruz. Disponível em: <http://www.epsjv.fiocruz.br/index.php?Area=Entrevista $\& N u m=22>$. Acesso em: 21 fev. 2014.

IBGE. IBGE CIDADES: Paraíba - Santana de Mangueira. Disponível em <http://www.cidades.ibge.gov.br/xtras/perfil.php?lang=\& codmun $=251350 \&$ search $=$ paraiba|santana-demangueira|infograficos:-informacoes-completas>. Acesso em: 25 out. 2014 .

LONDRES, Flavia. Agrotóxicos no Brasil: Um guia para ação em defesa da vida. Rio de Janeiro: Ana - Articulação Nacional de Agroecologia Rbja - Rede Brasileira de Justiça Ambiental, 2011.

MINISTÉRIO DA SAÚDE. Brasil notificou 208,8 mil casos de intoxicação por agrotóxicos em 25 anos. Disponível em:

<http://portalsaude.saude.gov.br/index.php/profissional-egestor/vigilancia/noticias-vigilancia/172-noticiasanteriores-vigilancia/7815->. Acesso em: 29 abr. 2014.

MOREIRA, Marco A.. Subsídios Metodológicos para o Professor Pesquisador em Ensino de Ciências: Pesquisa em Ensino: métodos quantitativos e qualitativos. 2009 Disponível

<http://www.if.ufrgs.br/ moreira/Subsidios11.pdf>. Acesso em: 10 nov. 2014

PERES, Frederico; MOREIRA, Josino Costa. Saúde e ambiente em sua relação com o consumo de agrotóxicos em um pólo agrícola do Estado do Rio de Janeiro, Brasil. Disponível em: <http://www.scielo.br/pdf/csp/v23s4/13.pdf >. Acesso em: 02 maio 2014

PORTO, M. F. Modelo de produção agrária no Brasil Seminário de Enfrentamento aos Impactos dos Agrotóxicos na Saúde Humana e no Meio Ambiente. Rio de Janeiro: Fiocruz, 4/6/2012.

PRESIDÊNCIA DA REPÚBLICA. Lei No 11.326, de 24 de Julho de 2006. Estabelece as diretrizes para a formulação da Política Nacional da Agricultura Familiar e Empreendimentos Familiares Rurais. Brasília, DISTRITO FEDERAL.

PRESIDÊNCIA DA REPÚBLICA. Lei $\mathbf{N}^{\circ}$ 7.802, de 11 de Julho de 1989. Brasília, DISTRITO FEDERAL. 